\title{
RESEARCH OF FUZHOU HISTORICAL BUILDING MANAGEMENT PLATFORM BASED ON DATA WAREHOUSE TECHNOLOGY
}

\author{
W. B. $\mathrm{Li}^{1}$ ， G. L. Li ${ }^{1}$, Y. Yang ${ }^{2}$ \\ ${ }^{1}$ Beijing Tsinghua Tongheng Urban Planning and Design Institute, Beijing, China - (liwenbin, ligongli)@thupdi.com \\ ${ }^{2}$ Fuzhou Historic City Management Committee, Fuzhou, China - mcwbxc@163.com
}

Commission II, WG II/8

KEY WORDS: Data Warehouse, Historical Building, Fuzhou, Management Platform, GIS, H5

\begin{abstract}
:
In order to solve the problem of "data island" in the management of Fuzhou historical buildings. This paper analyzes historical building management needs and historical building management indicators. Then the data warehouse model of historic buildings is constructed by using dimension modeling method, and a set of data warehouse of Fuzhou historic buildings is designed and established. Finally, a historical building management platform was built on the basis of the historical building data warehouse, which realized the entry, standardization, extraction and cleaning of historical building management data. It provides data support for data mining of historic buildings in order to realize the protection, activation, utilization and standardized management of Fuzhou historic buildings.
\end{abstract}

\section{INTRODUCTION}

Fuzhou is the capital city of Fujian Province in China. It was built in $202 \mathrm{BC}$ and has a history of more than 2,200 years. In 2017, Fuzhou City and County Government announced the first batch of 426 historical buildings, which are characterized by various types and the current situation is complex. In addition, the management data of historical buildings, such as the inspection data of historical buildings and the construction review data, are often independent of each other and do not form a connection, resulting in "data island", which makes the data unable to play a real role. Therefore, through the data warehouse technology, the original data is integrated and analyzed, which provides a data foundation for deep mining of data rules and early detection of historical building damage trends, so as to solve the problem of "data islands" under the current system, and make the data play its important value.

\section{HISTORICAL BUILDING MANAGEMENT INDICATORS}

Before constructing the data warehouse, it is necessary to sort out and analyze the index system of Fuzhou historical buildings. According to Fuzhou historical building status, historical building plans and historical building management business needs, the historical building management index system is established. As shown in Figure 1, the historical building management index system is mainly divided into historical building basic information, building management information, inspection management information, Construction review management information. The historical building basic information mainly records the name, age, style and property rights of the building; the building management information mainly records the building management department, the building responsibility main body and the building protection identity related information. The inspection management information records the daily inspection and reporting information of the staff, including whether the overall condition of the building is good, whether there are major security problems, whether there are improper construction activities, and so on. Construction review management information mainly records the daily maintenance, emergency repair, original site repair and migration protection project information of historical buildings. 


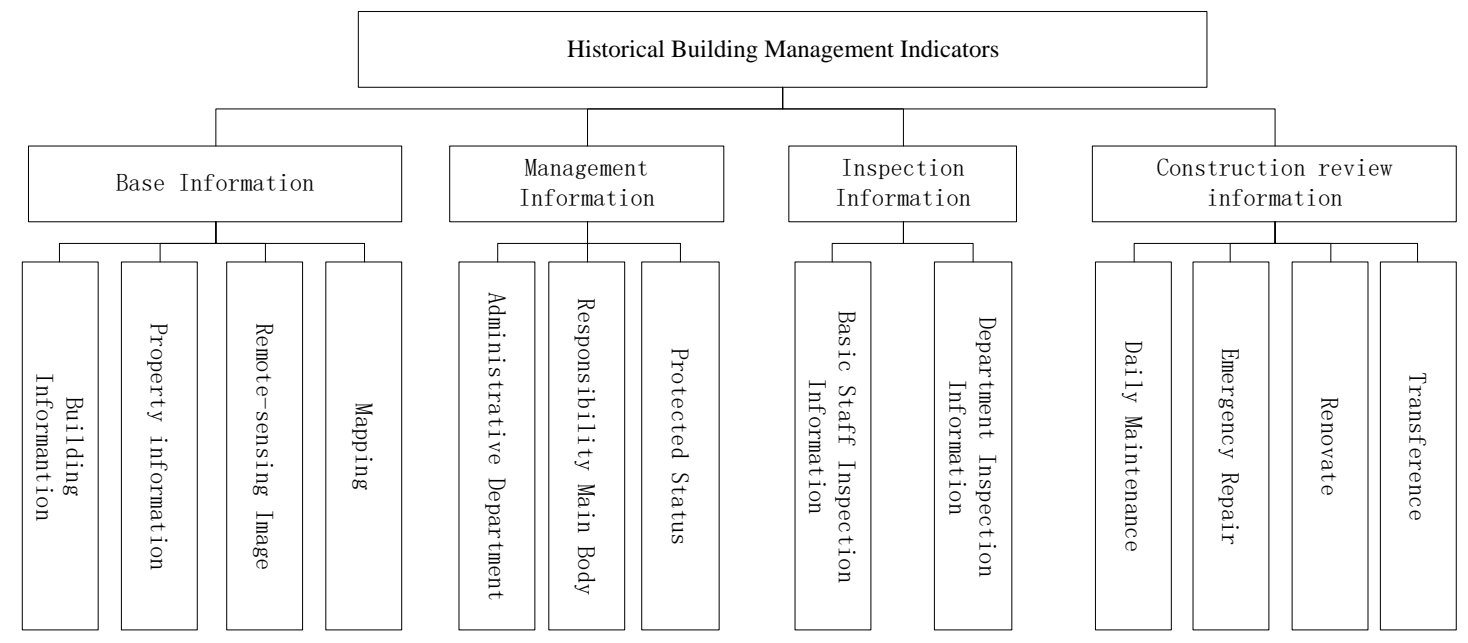

Figure 1. Historical building management indicators

\section{HISTORICAL BUILDING DATA WAREHOUSE CONSTRUCTION}

\subsection{Data Warehouse Introduction}

The data warehouse is a large-scale data accumulated by the organization through the online transaction processing (OLTP) of the information system. Through the data storage architecture unique to the data warehouse theory, it is a systematic analysis and support. Analytical methods such as online analytical processing (OLAP), data mining and other follow-up work, and in turn support the creation of such as decision support systems (DSS) and executive information systems (EIS). Data warehousing helps decision makers quickly and efficiently analyze valuable information from large amounts of data for decision making and rapid response to external environmental changes. Data warehouse is a topic-oriented, integrated, timevarying, non-volatile data collection (Pelekis et al., 2008). The data warehouse extracts, cleans, processes, and aggregates heterogeneous, independent business data (Long et al., 2013). It is stored in time series to provide a data foundation for subsequent statistics and data mining.

\subsection{Data Warehouse Structure Design}

The data warehouse is used to fully receive the data collected by the source, and the data is normalized, verified, cleaned, and finally loaded into the data warehouse through the ETL (ExtractTransform-Load) process. The entire data warehouse is divided into four levels (Ma et al., 2013).

1. SSA (system of records staging area): The SSA directly copies the data of the source system and tries to maintain the original appearance of the service data. The only difference from the source system data is that the data in the SSA adds timestamp information to the source system data, forming multiple versions of historical data.

2. SOR(system of record): SOR is a set of table structure based on $3 \mathrm{NF}$ paradigm rules developed by the model. It stores the most detailed data in the data warehouse and stores the data according to different subject domains. For example, in the historical building management system, according to current needs. The historical building data is stored in the SOR layer according to the four themes of basic information, spatial information, patrol information and construction review information; SOR is the core and foundation of the entire data warehouse, and should be flexible enough in the design process to cope with Add more data sources, support more analysis needs, and support further upgrades and updates.

3. SMA (summary area): SMA is the intermediate transition between SOR and DM (data mart). Since SOR is highly normalized data, it takes a lot of correlation work to complete a query. At the same time, the data granularity in DM is often much higher than SOR. The aggregated data requires a lot of summarization work. In this way, SMA makes a moderate antiparadigm of SOR data according to requirements (for example, designing a wide-table structure to combine data from multiple tables such as building information and property rights information) and summarizing (for example, some Common header summaries, management department summaries, etc., to improve data warehouse query performance.

4. DM (data mart): Data saved by DM can be accessed directly by users. DM can be understood as the data/DM that end users want to see is mainly all kinds of granularity data. By providing different granularity data, it can meet different number access requirements. Data in historical building management system's DM can be stored in two different types, one is a star model, which is convenient for the daily flexible query and statistics of the management department, and the other is a wide table and reorganized table structure storage for the fixed report. It is convenient for quarterly and annual statistical work of historical buildings.

\subsection{Data Warehouse Construction}

To construct a historical building data warehouse, we first need to determine the theme in the data warehouse (Kimball, Ross, 2011). According to the business characteristics of Fuzhou historical building management, this paper defines a public dimension theme and three main business themes: historical building, inspection and construction review. Public dimensions include time dimension, geographic dimension, and standard dimension. Time dimension and geographic dimension can be converted to specific analysis dimensions using view, and standard dimension is used to solve the consistency problem in data integration process.

The historical building theme mainly records the name, address, 
dynasty, and height of the historical building. The inspection theme mainly records information such as the inspection time, the buildings being inspected, and the problems existing in the building. Construction review theme mainly records daily maintenance, emergency repair and other information.

Second, after defining the themes in the data warehouse, we need to determine the granularity of the analysis object. In order to make the data warehouse have good scalability, in principle, the data model should be designed with the minimum granularity. For example, when designing a historical building model, the structure, height, age, and protection plan of the historical building should be recorded as much as possible.

The third step is to design a dimension table, which is mainly for statistical analysis, which corresponds to the parameters of the statistical query. Extract all important attributes related to the statistical object as independent dimensions. For example, the historical building section dimension records the historical location, the location range, and the location management department where the historical building is located.

The final step is to design the fact table. In order to track the change process of the activity data with life cycle to retain the historical information, the fact table should be designed to capture the change data by using slowly changing dimensions (Gao, 2012). The three fields of version, start time and end time in the fact table are the core to achieve slow changes. For example, in the information table of historical building ontology, whenever the information of a historical building changes (e.g. the owner of the historical building changes), a new version is generated. The start time is the generation time of the version, and the end time is the generation time of the next change. Through the above four stages, the data warehouse of Fuzhou historical buildings is finally constructed. Figure 2 is a star model of historical building theme.

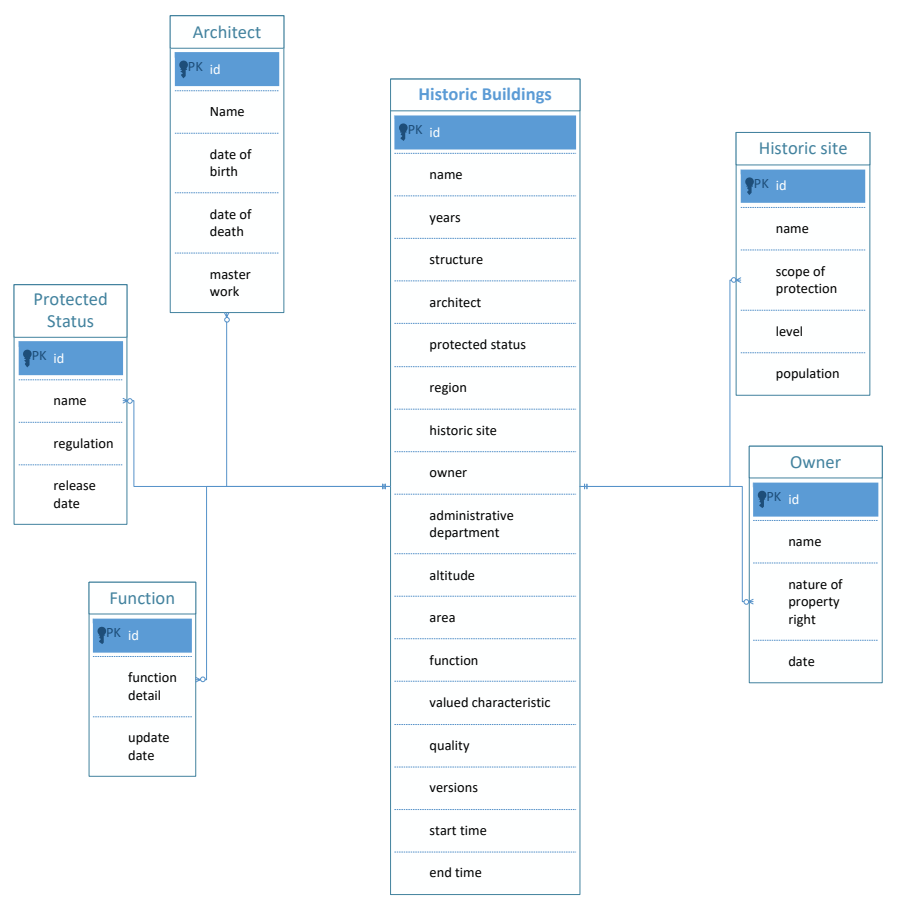

Figure 2. Star model of historical building theme

\section{HISTORICAL BUILDING MANAGEMENT PLATFORM}

Based on Fuzhou historical building data warehouse, we designed and developed a set of historical building management platform. The platform adopts $\mathrm{B} / \mathrm{S}$ architecture and consists of web system(client), server system and data warehouse. Spring Boot framework is used in server system and Mybatis framework is used in persistence layer. It is mainly responsible for extracting business data and statistical data from data warehouse and transmitting them to web system. The web system is responsible for displaying historical building data and its statistical results. Based on the latest H5 and GIS technologies, the web is developed using the open source front-end framework Vue and the map framework Openlayer to realize the historical building data warehouse data display and statistical data display functions.
This platform is mainly divided into one map of historical buildings, inspection management, and construction review management modules. One map of historical buildings mainly realizes the whole life cycle management of historic buildings based on GIS, including the retrieval, query and statistics of historic buildings, and browse and edit information such as basic information and protection information of historical buildings. In the patrol management module, the historical buildings can be inspected, the patrol records can be filled in, and the patrol photos can be uploaded, so that the managers can discover the problems and hidden dangers of the historical buildings in time. The construction review module mainly manages the maintenance and repair works, the rescue and reinforcement projects, the repair works and the migration project information of the historic buildings. 


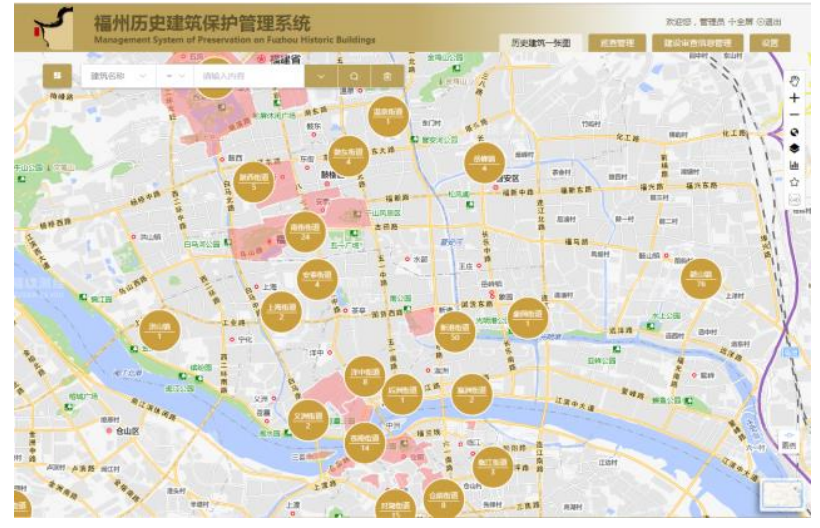

Figure 3. One Map of Historical Building

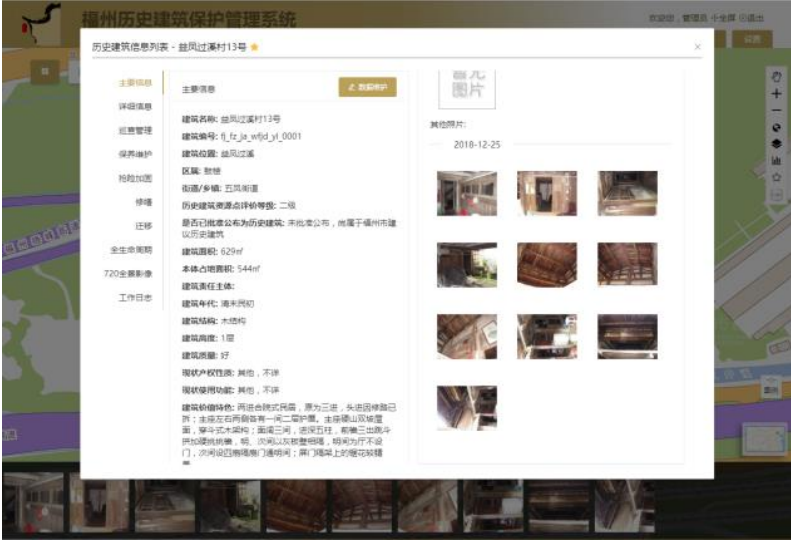

Figure 4. Information Display of Historical Building

\section{CONCLUSIONS}

In summary, this paper proposes a construction scheme of historical building management platform based on data warehouse. Through reasonable architecture design and scientific data modeling, the functions of centralized storage, processing, display and statistics of historical building data are realized. The platform can effectively solve the problems of different data quality and isolation in the management of traditional historical buildings. The platform meets the business development needs of historical building management, improves the historical building management level, and lays the data foundation for historical building data mining, so as to realize the protection, activation, utilization and standardized management of historical buildings in Fuzhou.

\section{REFERENCE:}

Pelekis, N., Raffaetà, A., Damiani, M., -L., Vangenot, C., Marketos, G., Frentzos, E., Ntoutsi, I., Theodoridis, Y., 2008: Towards Trajectory Data Warehouses. Mobility, Data Mining and Privacy, Springer Berlin Heidelberg, 2008. doi.org/10.1007/978-3-540-75177-9

Long, X., Z., Li, L., Peng, Y., M., Wang, Q., Y., Ouyang, R., B., Liu, Y., F., 2013: Research of university data statistical platform based on data warehouse. Journal on

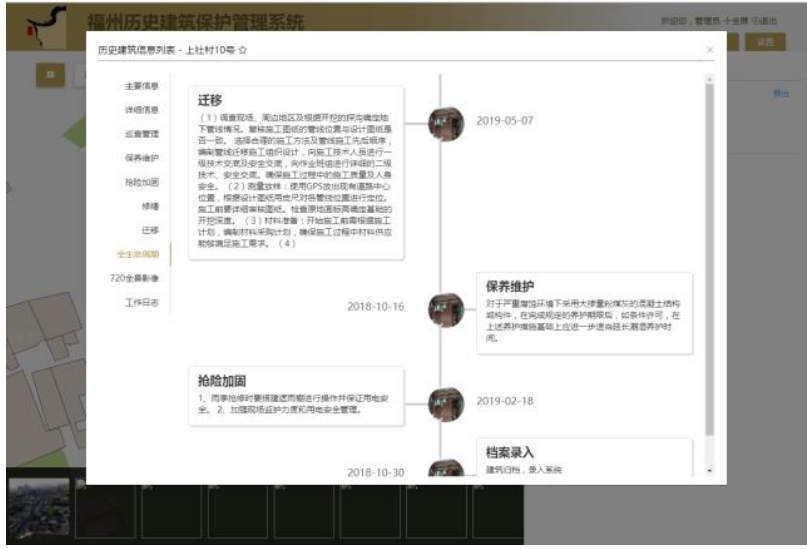

Figure 5. Full Life Cycle Management of Historical Buildings
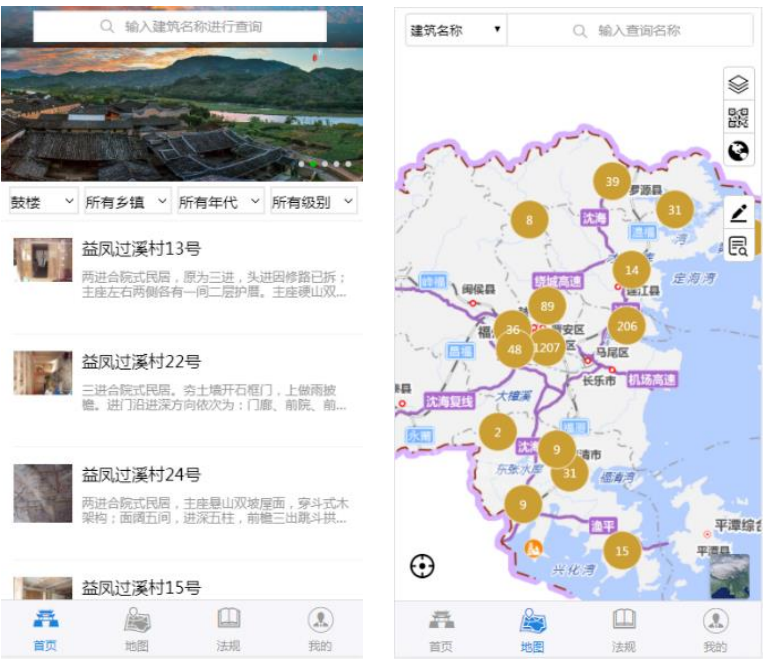

Figure 6. Mobile App based on H5

Communications.s2(2013):163-169

Ma, N., Cao, Z., LI, J., 2013: The Research on the bank superintendency reporting system based on data warehouse[J]. Software Guide.12(4):137-141.

Kimball, R., Ross, M., 2011: The Data Warehouse Toolkit: The Complete Guide to Dimensional Modeling, ACM SIGMOD Record 6.3,181-191.

Gao, L., 2012: The Research on the Construction of Data Warehouse in Universities. Journal of Wuhan University (Natural Science Edition). s1:179-184. 